\title{
Análisis del placer y la sexualidad matrimonial en Alonso de la Veracruz: \\ «De los actos de los cónyuges a causa del placer» \\ (Speculum Coniugiorum, III, art. 16)
}

\author{
Virginia Aspe Armella \\ Universidad Panamericana \\ vaspe@up.edu.mx
}

\section{Introducción}

Es sabido que la edición crítica del Speculum Coniugiorum de Alonso de la Veracruz la realizó Luciano Barp Fontana; la primera parte de la obra salió en el año 2009, la segunda y tercera, en el $2013^{1}$.

Una edición crítica de esa envergadura es un hecho sobresaliente en el mundo académico, pues surge de un texto incunable del siglo XVI que se transcribe, traduce y comenta; posterior a ese esfuerzo, la publicación facilita el análisis de contenidos que antes no habían visto su luz a plenitud. Después del texto monumental de Barp, esfuerzo similar al que en el De dominio infidelium et iusto bello de Alonso de la Veracruz

1 En este escrito seguiremos la tercera parte privilegiando especialmente el art. 16. 
realizó Roberto Heredia Correa en el 2007, es deseable que surja mucha bibliografía especializada en torno a la obra y sus contenidos. En la presente investigación me propongo a contribuir a dicho análisis reflexionando sobre la interpretación que tenía Alonso de la Veracruz de la sexualidad y del placer sexual en el matrimonio. Me reduciré exclusivamente al análisis del concepto a la luz del artículo 16 de la tercera parte del Speculum; es indudable que un análisis completo del tema rebasa en tiempo y espacio las pretensiones de mi análisis, recordemos que el Speculum es un tratado de casi mil páginas.

Una cuestión a aclarar, antes de entrar en el tema, es que la edición crítica de Barp Fontana facilitó mucho mi investigación pues cuenta con un detallado trabajo de seguimiento de los autores que siguió fray Alonso para este tema; así mismo, el texto documenta los pasajes de textos como la Suma Teológica que siguió Alonso, lo mismo hace respecto de la legislación civil y canónica que conocía, además, cita los pasajes básicos Escriturales del tema. Barp Fontana utiliza la edición complutense del Speculum de 1572 y no la mexicana de 1556; el punto merece aclararse al lector ya que en medio de esas fechas ocurrió el Concilio de Trento (1545-1563) que cambió muchas de las regulaciones sobre el matrimonio por lo que De la Veracruz tuvo que cambiar y adaptar pasajes del Speculum de la edición mexicana. La edición crítica de Barp señala con un asterisco los pasajes cambiados por el fraile, así que no es complicado cotejar qué había dicho Alonso en el texto de 1556 recuperando su sentir original. Conocer lo que Alonso dijo en la edición mexicana es clave pues, por ejemplo, en el artículo XII de la tercera parte del Speculum que trata de «qué se debe hacer en el matrimonio cuando uno de los cónyuges niega el consentimiento», Alonso tiene 
que añadir un pasaje nuevo a la edición mexicana de 1556 porque el Concilio de Trento negó la validez de los matrimonios clandestinos (Vera Cruz: 245. Sesión 24, art. 1), aunque Alonso argumenta que tales soluciones previas sí sirven para los infieles en tiempo de infidelidad, es el caso de los naturales de América a los que él llama neófitos ${ }^{2}$.

La estructura del Speculum Coniugiorum es bien definida. Cuenta con tres partes en las que se trata el tema del matrimonio: en la primera, Alonso analiza qué es el matrimonio en general; en la segunda diserta sobre lo que es el matrimonio verdadero. Esta parte resulta del máximo interés para la historia intelectual actual ya que, una vez que la primera parte del tratado definió el matrimonio, describe en la segunda lo que era el matrimonio para los purepechas michoacanos y para los aztecas mexicanos concluyendo que entre los indios del nuevo mundo sí habían matrimonios verdaderos. Por último, la tercera parte, trata sobre matrimonio y divorcio ya que éste se practicaba entre los indios y Alonso tenía que estudiar las razones por las cuales se llevaba a cabo. En términos generales, el Speculum Coniugiorum es una obra de máxima trascendencia pues Alonso toma el criterio de la ley natural como el principio rector que guía sus valoraciones respecto de las alianzas indígenas. Y si hubo auténticos matrimonios entre los indios antes de la llegada de los españoles y antes de que conocieran la nueva ley evangélica, como efectivamente sostiene la obra que los hubo, ello implicaba que los indios de América eran plenamente racionales antes de ser bautizados pues vivían de acuerdo con la ley natural.

2 Por esta razón cotejé no sólo la edición de Barp Fontana sino la Antología previa que realizaron Carolina Ponce, Yail Medina y Leslie Martínez ya que ellas trabajaron la edición mexicana de 1556 (Ponce, 2007). 
Comienzo mencionando qué fuentes sigue el texto: cabe decir que estamos frente a una obra de clara impronta medieval que sigue textos Escriturales, Padres de la Iglesia, la Suma Teológica y comentarios a las obras de Aristóteles por Tomás de Aquino, y en menor medida, la obra sigue a Escoto, Ockham y los nominales de tiempos de Alonso en la Universidad de París y Salamanca como Guillermo de Ockham, John Maior, Almain y Juan de Celaya. Muy relevante es la influencia de algunas obras sobre el matrimonio, en concreto la de Miguel de Medina, religioso franciscano (1489-1578) que asistió al Concilio de Trento y al que Alonso cita constantemente con su obra De Caelibato ${ }^{3}$.

Medina fue discípulo de Alfonso de Castro (1495-1558); Barp Fontana nos dice que fue un franciscano llevado a Brujas por los comerciantes españoles de Flandes para contrarrestar las doctrinas luteranas (Barp, 2009).

El punto no es anecdótico, refleja la mentalidad de la época que hemos de tener en cuenta al enfrentar el Speculum Coniugiorum. De Castro fue al Concilio de Trento en 1547 y en 1568 publicó su tratado De Sorilegiis et malefiiseorumque punitione diciendo que el matrimonio de Enrique VIII con Catalina de Aragón era válido. El punto nos sirve para encuadrar el contexto del Speculum de fray Alonso pues todos los grandes intelectuales de su época escribieron tratados sobre el matrimonio, ora en ocasión de Enrique VIII y su divorcio de Catalina, ora por las regulaciones impuestas al matrimonio en el Concilio de Trento intentando dar con ello respuesta a las reformas de Lutero en esa problemática. Trento se llevó a

3 Así lo sostiene Yail Medina en su «Investigación e Información de autores y citas», con un cauto «al parecer es la obra De Caelibato que Alonso cita continuamente» (Ponce; 2007: 206). 
cabo en tres periodos entre 1545 y 1563, abarcó a tres Papas, y tuvo como redactor de decretos matrimoniales a un español, Diego Covarrubias, quien en De Reformatione redactó conclusiones sobre desponsorios y nupcias. En la Sesión XXIV del Concilio de Trento se expresa la doctrina sobre el matrimonio ${ }^{4}$.

Una revisión de los Cánones Tridentinos sobre el Sacramento del Matrimonio (4-11) muestra que el interlocutor era prioritariamente Lutero pues los cánones sostienen que la Iglesia pudo establecer impedimentos dirimentes del matrimonio (can.4), expone razones de porqué el vínculo del matrimonio no puede disolverse en casos que Lutero había aceptado el divorcio (can. 5, 6, 7, 8), niega que los clérigos puedan contraer matrimonio (can. 9), y niega con san Pablo tanto que el estado conyugal deba anteponerse al estado de celibato como que el celibato y la virginidad sean mejores que el matrimonio (can. 10). Un último punto respecto a las fuentes que sigue el Speculum Coniugiorum es el uso reiterado de criterios legislativos canónicos y civiles. Como hombre de su tiempo que vive el renacimiento, Alonso sigue y cita clásicos latinos tanto como medievalistas canónicos y juristas romanos del Corpus Iuris Civilis.

En cuanto a la estructura interna de la obra, estamos frente a un texto de impronta tardo-medieval que ha recuperado los avances del nominalismo en cuanto al enfoque de los problemas concretos, del uso de fuentes y de la selección de autores; el Speculum es una obra pos-renacentista que recupera la tradición latina, expone con claridad lingüística, privilegia el derecho romano y realiza ocasionalmente una exégesis bíblica apoyada en la historia, como cuando dice

4 La edición crítica del Speculum de Barp Fontana incluye dentro de su Indice Onomástico los Cánones Tridentinos sobre el sacramento del matrimonio. 
que a pesar de que Tomás de Aquino, Escoto y Cayetano digan algo, él se apoya más en el criterio de los santos padres o en opiniones que tiene respecto de cuestiones que son prudenciales.

Pero si es verdad que en la época surgieron múltiples tratados sobre matrimonios, ninguno de ellos contó con la extensión que tiene el Speculum; Alonso entendió bien que la relevancia de la problemática residía en la nueva realidad americana: neófitos sobre el tema, los indios de América practicaban a su manera los matrimonios, legislaban y normaban sobre sexualidad y divorcio; además, estaba el problema de la poligamia y la iglesia tenía que dirimir sobre en cuál de las parejas había verdadera unión; estaba también la práctica de las relaciones sexuales y matrimoniales consanguíneas y el tema de los diversos ritos y de la ausencia de un signo externo matrimonial. No me voy a detener ahora en estas importantes cuestiones que he abordado en otro momento (Aspe, 2016a y 2016b), ahora me interesa entender cómo concebía Alonso la relación entre matrimonio, placer y sexualidad, mostrar que él hace esa interpretación basándose en el derecho civil y canónico de su tiempo, en el concepto tomista de ley natural y en algunos tratados europeos que se hicieron cargo de prácticas sexuales y de matrimonios ajenas al cristianismo, aprovechando lo que el Concilio de Trento reguló. 


\section{Antecedentes del artículo XVI de la tercera parte del Speculum}

Comencemos por exponer de dónde viene y hacia dónde va el artículo XVI de la tercera parte del Speculum. Hemos dicho que la tercera parte trata sobre matrimonio y divorcio. Para entender el tema del repudio, Alonso desarrolla veinte artículos analizando las causas de éste las razones, los modos y las consecuencias de que el marido o la mujer puedan despedir al cónyuge, da consejos sobre qué deba hacerse en casos específicos y, en el artículo XV, comienza a deliberar sobre los actos de los cónyuges en cuanto al modo del coito; en el XVI trata de los actos de los cónyuges a causa del placer y por otras razones, en el XVII trata si por razón de circunstancia de lugar y de tiempo, el acto del cónyuge puede ser un pecado. Los últimos tres capítulos tratan sobre si es lícito pedir débito cuando se duda si el cónyuge es verdadero esposo y de algunas cuestiones de obligación y ley de matrimonio y herencia. En nuestro caso, los artículos XV al XVII son relevantes. Aclaremos el significado de los términos que se involucran en este apartado: en un erudito rastreo, Barp nos dice que «el término divorcio está compuesto de dos raíces: $1 . D i$ (s), que significa separación; 2. Verto, vertis, versus, vertere, que indica dar vuelta, girar, tornar» (Bart, 2009: 67).

Alonso establece desde el primer capítulo que el divorcio se entiende de distinta manera en el derecho civil y en el eclesiástico; por el primero, se indica «la separación del matrimonio en cuanto al vínculo como aparece en el Digesto (24, $2,2) »$ en el que los dos cónyuges no son de una sola mente para permanecer viviendo juntos; en el segundo, «el divorcio se toma como la separación de los cónyuges en cuanto 
al lecho, permaneciendo íntegro el vínculo del matrimonio» (S.C. III-1: 79).

Alonso deliberará cuándo, de acuerdo con ambos derechos, ocurre la separación del lecho o de la cohabitación permaneciendo íntegro el vínculo del matrimonio; es decir, no le interesa la perspectiva de la disolución del matrimonio, sino las razones por las que está validada la separación física de los cónyuges, ya que asentó en la primera parte del tratado que sólo Cristo, que instituyó el matrimonio, podría disolverlo.

El capítulo primero de la tercera parte nos da las causas del divorcio y los modos en que se disuelve un matrimonio entre los infieles, aclarando que estos pueden disolverse en cuanto al lecho y en cuanto a la cohabitación ${ }^{5}$.

Recordemos que el interés de Alonso es en ocasión de los matrimonios de indios de América que tenían problemas muy diversos a los europeos por la práctica de la poligamia, la ausencia del conocimiento de las regulaciones del derecho civil y canónico europeo y la diversidad en usos y costumbres. Alonso explicita en cada ocasión si la disolución matrimonial es para infieles o si refiere sólo para fieles. Respecto de la disolución del matrimonio por razones de lecho y cohabitación Alonso da seis conclusiones válidas: la primera, dice que «respecto del lecho y para fieles que contrajeron legítimamente la causa es la fornicación». Dos puntos merecen comentarse de esto: primero, que deja fuera la disolución para los infieles porque Alonso considera que sólo quienes han recibido la plena luz del evangelio pueden caer en culpabilidad moral por esta causa. Para Alonso, como veremos a continuación, la fornicación es la causa del divorcio pero él tratará de las razones por las que ella puede no ser imputable

5 En adelante citaré la obra bajo las siglas S.C. 
en los indios americanos, hablará de desviaciones en preceptos derivados o de principios segundos de ley natural pues sigue la interpretación tomista de que la ley natural, rige de modo necesario y evidente entre los hombres sólo en cuanto a sus primeros principios, ya que los derivados pueden ser obstaculizados por la cultura, la educación, la tradición y las costumbres diversas. Volveremos sobre este punto más adelante, basta con enunciarlo por ahora. Un segundo punto a notar en la sentencia es que la causa del divorcio es por una desviación de la sexualidad en el matrimonio; uno pudiera haber esperado también la enunciación de algún vicio o desviación de otro tipo, como el de la soberbia o el de la falta de compatibilidad en la obra conjunta, pues para Alonso los fines del matrimonio son la generación, la educación de la prole y el libre, voluntario y consciente compromiso de obra conjunta, pero ni el segundo ni el tercer fin se consideran causa de divorcio en estos artículos, por lo que vemos que la desviación de la sexualidad, cara a la generación de la vida, se erige como el fin primero del recto obrar humano conyugal. La exigencia que hacemos no es anacrónica pues el mismo Tomás de Aquino había considerado estas cuestiones en pasajes que sabemos que Alonso conocía porque los cita ${ }^{6}$.

Como iremos desentrañando en este escrito, De la Veracruz ubica la sexualidad para la generación como el principio último del matrimonio, siempre y cuando lo anteceda el libre consenso entre los cónyuges. Alonso centra el tema del divorcio a partir del fin del matrimonio desde la perspectiva de la especie, la generación de los hijos, y a partir de criterios

6 Por ejemplo, es relevante el Tratado de los vicios y los pecados de Tomás de Aquino en la S.Th., I-IIae., q. 74 a 8. 
en derecho, en el caso del matrimonio, en razón del débito conyugal 7 .

Acude a la autoridad evangélica de Mateo $(5 ; 19)$ siguiendo la norma canónica de que sólo Cristo puede disolver lo que instituyó. Pero Alonso añade una reflexión retórica para explicitar las palabras de Cristo: «Pues, ¿quién tranquilamente soportaría que su esposa adulterase habitualmente y que éste mismo no pudiese abandonarla?», siendo ese argumento la primera razón que justifica la separación del lecho y la suspensión del débito; y después enuncia la segunda, porque la fornicación se opone a un bien del matrimonio que es la fidelidad «que los cónyuges están obligados a conservar entre sí para que nadie acceda al lecho ajeno» (S.C., III-1: 83). Y da la tercera razón, por caridad, ya que si el marido no abandonara a la mujer que fornica «le daría una razón para fornicar». Da la cuarta que considera más importante: por el bien de la prole, «en efecto, fornicando la esposa, la prole nacería de padre incierto» (Casaneo. Oiureurando, c. Quemadmodum. X. 2.24.25.).

Además de la fornicación, Alonso da otra causa legítima de disolución matrimonial: la impudicia o vicio de la sodomía que puede darse tanto de modo activo o pasivo como uniéndose carnalmente con la esposa fuera del vaso natural, es decir, por otra vía que no sea la vaginal. Para Alonso, tanto la impudicia como el vicio de bestialidad al realizar el acto sexual contra natura, forman parte de la fornicación, ambos son pecados graves y causa de divorcio porque van en contra del fin del matrimonio que es la generación y «conocerse

7 Es obvio que además de estas cuestiones, Alonso considera la validez del matrimonio desde la perspectiva formal del contrato y sus signos, pero ahora no me interesa detenerme en ese punto. Para ello confrontar la primera parte del Speculum, arts. S.C., III-1: 81. 
carnalmente a plenitud en el modo debido». Lo mismo para aquellos que no se entregan a la mujer esposa de la manera debida ya que «fuera del vaso debido se impide la generación» (S.C. III-1: 83).

Para este criterio conviene recordar que, en la primera parte del tratado (art. 1), fray Alonso estableció que el matrimonio es la unión voluntaria, libre y consciente de uno con una, teniendo como fines la generación natural, la educación de la prole y la ayuda mutua (S.C. I ,1:55-57). Establece como punto de partida del matrimonio que fue instituido por Dios desde que vio a Adán solo y decidió darle una compañera «como ayuda semejante a sí mismo» (S.C. I-1: 55).

Y sólo después del pecado original, el matrimonio se tomó como un remedio a la concupiscencia. La tipificación surge a partir de la naturaleza caída del hombre, es decir, es la concupiscencia la que protagonizará en última instancia, la regla matrimonial. Además, Alonso señala en la primera parte del Speculum que el matrimonio es un derecho natural en el sentido específicamente humano pues tal finalidad no es causada por instinto como en los animales sino «por la voluntad mediante libre consentimiento» (S.C. I-1: 59).

\section{Ley natural y fines del matrimonio en el Speculum}

Cuando en la primera parte del tratado ahondó sobre este punto, precisó que el hombre está inclinado, por naturaleza, al matrimonio en el sentido en que su perfección depende del libre albedrío mediante consentimiento. Notemos que, en su criterio, no es la mera sexualidad cara a la generación la que involucra su criterio, pues sostiene que la clave del matrimonio está en el juicio de la razón y no en una necesidad natural a la manera en que la piedra cae necesariamente 
hacia abajo, es decir, su interpretación de la sexualidad humana es diversa a la común con los animales. Por esa razón, Alonso argumenta que tal unión voluntaria que es matrimonio no solamente dura el tiempo que dura la unión carnal sino el tiempo que implica la educación de la prole 8 .

Así, la necesidad del matrimonio le viene por sus fines: la generación, la educación de la prole y la obra conjunta de los cónyuges de tal manera que todas las valoraciones que Alonso hará de la sexualidad y del placer en el matrimonio estarán subordinadas a esa triple finalidad que principia en el libre consentimiento de la pareja. El punto tiene su sustento en la ley natural de Tomás de Aquino cuestiones 90 a 94 de la I-IIae de la S.Th., donde el dominico sostuvo tres principios de la ley natural: la defensa de la vida propia y ajena, la educación de los hijos y la sociabilidad humana.

La argumentación inicial de la tercera parte que nos ocupa sigue la tradición cristiana de san Mateo, san Pablo, san Agustín, el Crisóstomo, Tomás de Aquino, Calderino, San Antonio de Florencia, el abad Panormitano, Juan Andrés en Maritis, Extra, De adulterio, x.5.16.4; Barbatoius en 1. Vol. Consiliorum, cons. 64; Casaneo, en In consuetudine (éste el más citado de todos) sigue también al Burguense, Alciatus, al Papa Inocencio III en su tratado De adulterio, y a Álvaro Pelayo en De plancta Ecclesiae, lib.2, ar. 2.

Una tercera conclusión sobre causas legítimas de divorcio como repudio que da el fraile es en razón de herejía en uno de los cónyuges. No me detendré en ésta porque no es

8 (S.C. I-1: 63). Éste es un punto interesantísimo en el fraile pues considera que una vez que los cónyuges han concluido la tarea educativa podrían dejar de cohabitar por diversas razones. En el apartado que desarrolla ese punto sí aparece una causa de separación distinta a la de la desviación sexual cara a la generación. 
tema de mi interés ahora, basta con señalar que Alonso da las causas legítimas de la separación por cohabitación, aclarando que las previas fueron las únicas que estableció Cristo y que no hay otras aunque añade el caso de herejía no por ser una fornicación espiritual sino porque la Iglesia socorre al fiel que padece al cónyuge en herejía pues

si no se diese al fiel la licencia de separarse del cónyuge hereje, el cónyuge fiel se apartaría de la fe a causa de la convivencia mutua y de la unión carnal. En efecto, participando de las cosas venéreas sería fácil el alejamiento (S.C. III-1: 87).

En la razón vemos que Alonso considera que la práctica sexual matrimonial aporta intimidad y compatibilidad humana entre los cónyuges, ya que incluso llega a pensar que la herejía de uno puede llegar a introducirse en otro en la medida en que los actos sexuales compenetran a ambos cónyuges en la relación.

Alonso enuncia después en qué situaciones no es necesaria la separación, da siete casos en los que, aunque se conceda el divorcio a causa del adulterio, hay razones particulares que lo impiden: si ambos cónyuges cometieron adulterio, si el marido dio a la mujer ocasión de adulterar, si la mujer o el marido creyeron que su marido había muerto y se casaron con otro, si la mujer sin saberlo se unió a un hombre que creyó que era su marido y resultó no serlo, si la mujer se unió carnalmente con violencia, si el marido se reconcilió con la esposa adúltera uniéndose carnalmente con ella después de que supo de ella y cuando el adulterio ocurrió antes de la conversión a la fe; este último punto reiterativo de que la ley no regía de la misma manera a creyentes y neófitos. Notemos aquí que la 
violencia del marido, así como el furor, son causas suficientes de divorcio. Estas cuestiones las apoya De la Veracruz en el criterio de Palacios Rubio y las conclusiones tridentinas de Covarrubias. El punto sobre furor y violencia resultan importantes porque prueban que, respecto del débito conyugal, es errado inferir que la interpretación cristiana de la sexualidad en todos los canonistas consideraba que la mujer estaba sometida ilimitadamente al arbitrio sexual del marido, sino que éste tendría que conducirse con equidad a su mujer y sin vehemencia. Notemos que Alonso sigue en esto el criterio de las regulaciones tridentinas (S.C. III-1: 95- 97).

Se vislumbra en Alonso una igualdad de criterios a la hora de valorar las conductas sexuales del matrimonio; ciertamente en los primeros dos artículos de la tercera parte que nos ocupa, el fraile habla de la legitimidad del marido para despedir a la mujer, y en el artículo 2 reitera que es obligación del marido despedir mediante divorcio a la esposa fornicaria, a menos que tenga certeza de que, alejándola de él, ella empeorará (S.C. III-2: 99).

Pero en el artículo tercero Alonso concluye que esos criterios valen tanto para la mujer como para el marido y dice que la mujer también puede acusar a su marido de adulterio, y da la primera conclusión: «Dado que el marido y la esposa, en cuanto a aquellas cosas que se refieren al matrimonio, están obligados a lo mismo, el divorcio se hará a causa de la fornicación del marido, así como de la mujer». Añade que el marido tiene el deber de dar el débito a su esposa cuando ella se lo pide. Y no sólo eso, sino que cuando el marido fornica es aún más grave porque él es cabeza de familia y habría de dar mejor ejemplo. Sin embargo, Alonso considera aún más grave el adulterio en la mujer porque hace incierta la 
procedencia de los hijos, concluyendo que hay equidad en la culpa de ambos, aunque por diversas razones?.

Alonso aclara que el débito conyugal rige cuando el cónyuge sigue los fines del matrimonio, que todas las cosas prohibidas en la sexualidad marital son cuando la relación sexual impide los fines conyugales, aclara que no se exige que el cónyuge refiera en cada relación sexual a los fines del matrimonio, sino que basta con que virtualmente haya decidido seguirlos. En la sexta conclusión delibera sobre si es pecado realizar con frecuencia el acto carnal en el matrimonio y allí sostiene que ello depende de la intención con que esto se haga, si es para la generación de la prole, si es por libido o si es para evitar la fornicación en uno mismo ${ }^{10}$.

Pasemos ahora al artículo XV que es el último que nos sirve de preparación para, en el próximo apartado, desentrañar el concepto alonsino de sexualidad y placer en el matrimonio. En el artículo XV, De la Veracruz trata De los actos del cónyuge en cuanto al modo del coito, Alonso pasa a esclarecer el tema del débito matrimonial y sus consecuencias.

9 (S.C. III-3: 107-111). Ver RAE. Por fornicación se entiende «tener ayuntamiento o cópula carnal fuera del matrimonio». Por placer se entiende «goce o disfrute físico o espiritual producido por la realización o la percepción de algo que gustó o se considera bueno». San Pablo rige los criterios de sexualidad y placer en el tema del matrimonio cristiano. Ello no quiere decir que Alonso no haya dado una diversidad de interpretaciones en torno al tema, pero en general la interpretación viene de sus textos. Menciono al lector los pasajes paulinos más relevantes para comprender el tema que tratamos: En Corintios, 7,2, san Pablo dice que conviene que a causa de las fornicaciones cada uno tenga su propia mujer, su propio marido. Recomienda «huir de la fornicación» $(10,13)$. Sostiene importante que en el matrimonio se tenga una misma mentalidad y un mismo juicio. $(1,10)$. Pero al hablar de virginidad y sexualidad dice que cada uno tiene libertad para decidir si se casa o se mantiene en el estado casto $(6,12-19)$. En la tercera parte de la carta aclara que «esto lo digo más como concesión que como mandamiento» (III,6). «Os lo digo más como cosa mía, no del Señor» (III, 12). Y recomienda sobre la castidad y el matrimonio que conviene que cada uno se quede en el estado que se encontraba cuando lo llamó el Señor (III, 20).

10 Sigue en esto el criterio de Tomás de Aquino. S.Th., I-IIae, q. 88, art. 3 et 4. 
Aclaremos primero qué se entiende por «débito conyugal». Venido también de las Cartas de san Pablo, el débito significa el ius in corpus o el derecho del cuerpo que se obtenía mediante el matrimonio. En Corintios I, 7, 3-4, San Pablo sostuvo «el marido dé el débito a la mujer, y lo mismo la mujer al marido. La mujer no dispone de su cuerpo, sino el marido; igualmente, el marido no dispone de su cuerpo, sino la mujer». El matrimonio implicó para el cristianismo la donación total de los cónyuges, y esto exigía la donación plena del cuerpo ${ }^{11}$.

Por ello, Alonso delibera en el artículo XV (S.C. III-XV: 257-267), si es lícito a los cónyuges pedir y dar el débito en cualquier tiempo, lugar y modo, aclarando que esta donación supone necesariamente darse «en el vaso natural». Respecto del modo de ejercer el débito da una condición: que la mujer yazca siempre sobre el dorso y que el varón se recueste sobre ella. La razón que da es que dicha postura es la que sigue más fácil para el fin del matrimonio que es la concepción y tal postura retiene mejor el semen. Añade que así fue cómo la naturaleza determinó la anatomía humana para el coito y que cualquier postura diversa es indebida por inatural. Respecto del propio acto sexual, Alonso dice que éste siempre tiene que estar abierto a la vida, es decir, en función de la prole, y aclara que el acto se realiza, o para rendir el débito, o para saciar la libido, o para procurar y conservar la salud. Reitera que el criterio de bondad de la relación sexual matrimonial exige que los actos se den según la recta razón, es decir, de acuerdo con los fines establecidos por la naturaleza,

11 Para este tema se sugiere: Génesis, 1: 27-28; 2, 18-24; Mateo, 1, 18-25; Pablo de Tarso. Cartas. Romanos, 7, 1-14. Corintios, 11, 2; Efesios, 5, 22-23. Alguna bibliografía de apoyo es: Basevi (1992) y Carretas (1998). 
por lo que la desviación de sus fines como posturas para evitar la generación y unirse sexualmente fuera del vaso debido son pecado. Empero no le parece que la frecuencia en las relaciones sexuales maritales fuese impropia a pesar de que la tradición sostenía que el abuso de la práctica era pecado grave, Alonso sostiene que ello no grava ni como un pecado venial, aunque esto lo sostiene ambiguamente (S.C., III-XV: 261).

Por último, da la cuarta conclusión que es la que más nos interesa: dice que lo dicho vale para los fieles, pero que en el caso de los naturales de América y en aquellos casos en que no se educó de esta manera o en los casos que la naturaleza misma no lo mostró, no hay culpabilidad alguna siempre y cuando no se haya impedido la generación de la prole. Para el fraile, las prácticas sexuales en el nuevo mundo no eran inmorales, sino que procedían de una ignorancia invencible. Alonso pone los casos de «la polución con las manos» (masturbación) que los indios practicaban a veces sin pudor alguno, y explica que el modo, el tiempo y el lugar en el que ejercen sus prácticas sexuales no corresponden a un punto de ley natural en su primer principio, que sólo la generación de la prole y su educación, así como la obra conjunta, se consideran fines intrínsecos del matrimonio por lo que tales prácticas en los usos indígenas no correspondían a un principio primero y evidente de la ley natural, que tales actos eran de preceptos derivados o secundarios, aunque supone que debían seguirse una vez que el cristianismo los enseñase.

En la primera parte del tratado, Alonso hizo una distinción clave sobre los preceptos de la ley natural tomista argumentando que los principios secundarios de la ley no eran evidentes a todos los hombres y que sólo la educación de generaciones podría contribuir para que los asimilaran (S.C., IIIXV: 263). 
El recorrido de los pasajes alonsinos arroja una sorprendente luz sobre el concepto de matrimonio, divorcio y sexualidad. Recapitulando, podemos concluir que para el agustino, la causa del divorcio es la fornicación y adulterio de los cónyuges, pues aún el caso de herejía remite a la sexualidad ejercida entre la pareja cuya práctica hace que peligre en el otro su vida de fe y por eso se recomienda que el cónyuge deje de cohabitar con su pareja. Debe aclararse aquí que Alonso trata en esta tercera parte del tratado exclusivamente de las causas de divorcio por lecho y cohabitación, que enfoca su planteamiento a la luz del débito matrimonial adquirido libremente por los cónyuges. Alonso es explícito en que esas causas son las únicas que legitiman al divorcio. El texto no se introduce en el problema de la desviación del fin de la obra conjunta o de la educación de la prole y sólo acude a razones por la carnalidad en la pareja. Es verdad que Alonso exime de culpabilidad a las prácticas sexuales de los indios y que mantiene un concepto más abierto de ley natural pues no dice que rija de la misma manera en aquellos que no conocían las normas evangélicas. Empero, el texto presenta dos deficiencias: es falso que sea una sola postura de la relación sexual la que permite acceder a la generación, algo desconocido por el fraile. Además, en los criterios de separación y divorcio los argumentos no involucran explícitamente la importancia de la libertad en las relaciones conyugales, ciertamente reprueba la violencia o impedimento del libre consentimiento en sus argumentaciones, pero no considera otros obstáculos en contra de la plenitud del triple fin del matrimonio enunciado, casos como la violencia sobre los hijos, la falla en la educación paternal compartida o algunas contradicciones de fondo en cuanto al modelo educativo o de vida familiar. Respecto de la consideración misma de la 
sexualidad, el texto muestra una consideración igualitaria entre el varón y la mujer, pero considera la sexualidad un deber exigido en el que las pasiones, el placer y el diálogo están ausentes. Se habla de los hijos como el fin primero del matrimonio, empero, no parece haber una asimilación entre los padres y los hijos a la manera en que se forma una familia. El enfoque está en las autoridades que deciden «en derecho» sobre la pareja, pero en ningún momento se acude al consejo de los sabios o expertos, a un seguimiento espiritual o anímico de sus miembros. El tratado se muestra como un texto «en derecho» romano y canónico; ciertamente, en otras partes del Speculum hay consideraciones familiares, por ejemplo, cuando en la primera parte del tratado, Alonso sostiene que la responsabilidad educativa del padre es informativa y la de la madre es formativa. Allí dice qué, pero si el texto desciende a tanto detalle en las cuestiones sexuales, no queda claro por qué no lo hace en otros ámbitos de la finalidad conyugal. El problema se esclarecerá en el siguiente y último apartado, donde en el artículo XVI, Alonso trata del tema del placer.

\section{Placer sexual, matrimonio y divorcio} en De la Veracruz, art. XVI, tercera parte del Speculum

Como venimos diciendo el artículo XVI trata De los actos de los cónyuges a causa del placer o por otras causas. Acerca de esto, Alonso se cuestiona sobre cómo se da el acto en aquellos que sí observan el modo natural de ejercerlo. Dice que pueden hacerlo a causa de la prole, a causa del placer y a causa de la salud $^{12}$.

12 A causa de la salud lo entiende para evitar la fornicación. 
Respecto de estas posibilidades Alonso dice que «dado que el hombre es incontinente por naturaleza» (S.C. III-XVI: 268-269), lo que resulta pecaminoso es buscar el acto sexual como mera búsqueda de placer; no reprueba el realizarlo por causa de la prole porque ése es el fin primero del matrimonio, ni reprueba que se haga por causa de la salud porque ello evita la fornicación ${ }^{13}$.

Acude al relato del paraíso de Génesis argumentando que antes del pecado de Adán y Eva se constituyó el matrimonio para una función pero que después del pecado, como lo explicó Alejandro de Hales, se instituyó como un remedio a la concupiscencia por el desorden ocurrido. Citando a $\mathrm{Mi}$ guel de Medina ${ }^{14}$, diserta sobre si el acto sexual por placer es pecado. El punto es delicado pues la tradición reprobaba el acto sexual por placer como una desviación del fin, y Alonso argumenta que si el acto sexual permanece dentro de los límites del matrimonio, es decir, si cae en el vaso adecuado, si está abierto a la generación y si la postura es la natural y recta, él considera que no puede calificarse de pecado mortal; menciona que San Alberto Magno (in 4 de 31) Maior (ibidem) Almain (in $4 d 26$ ) y Celaya ( $d 31$ ) no lo consideran ni siquiera un pecado venial, a lo que él no asienta pero dice que «por cierto es muy probable» (S.C. III-XVI: 277).

En la misma página del tratado, el agustino profundiza sobre este punto para esclarecer su duda diciendo que la relación por placer sólo sería pecado mortal si en el acto mismo el hombre pensara que «accedería a ella, aunque no fuera su esposa». El punto es relevante pues Alonso propicia la deli-

13 (S.C. III-XVI: 271). En este punto sigue a Durando, Maior, Valdense, Hugo de San Víctor, Almain, Celaya y Vitoria.

14 En De Coelibato, lib. 5. C. 77. 
beración para sentar un axioma respecto de la manera como debe entenderse el placer en la relación sexual matrimonial cuando dice que «nadie merece o desmerece por los hábitos, sino por los actos» y con ello establece su cuarta conclusión: «el acto carnal entre los cónyuges -respetando el vaso y el modo natural- nunca es pecado si se hace a causa de la prole o de rendir el débito». El punto le sirve para explicar lo que es el placer argumentando que, de suyo, lo que se hace a causa del placer no es ni bueno ni malo, siguiendo en esto a Aristóteles en E.N., X-5, a Tomás de Aquino en S.Th., I-IIae $q .74$ a 8 , y a Maior in $4 d$ 31. Las siguientes conclusiones las saca de este principio aclarando que basta con que los fines del matrimonio se tengan virtualmente para que la relación placentera sea válida y que la frecuencia del acto carnal que ocurre por causa de la generación de la prole, por libido o para evitar la fornicación en uno mismo, no es desviada. Alonso extrae derivaciones de esta nueva interpretación: en el artículo XVII trata de «si por razón de la circunstancia, de lugar y tiempo, el acto de los cónyuges puede ser pecado» (S.C. III-XVII: 282-289).

Expone que la iglesia había limitado las relaciones sexuales matrimoniales en días festivos, de ayuno y de comunión eucarística porque consideraba necesario el recogimiento y la oración para elevarse a Dios en días de fiesta, suspender los placeres en días de ayuno y en días de eucaristía evitarlos para lograr santidad y pureza (S.C. III-XVII: 283).

Después, se pregunta si durante el tiempo del embarazo es lícito pedir el débito, y si durante la menstruación hay que abstenerse del coito. Toda la exposición revisa lo que se ha venido normando y diciendo en torno al débito matrimonial para, al final, establecer otro axioma sobre la sexualidad y el placer matrimonial, que «acceder a la esposa exigiendo el 
débito sea para evitar la fornicación en sí mismo, sea a causa del placer, sea de cualquier manera, si se rinde el débito siempre se actúa bien sin pecado mortal ni venial» (S.C. IIIXVII, p. 289).

Tal parece que Alonso se propuso los siguientes objetivos en esta revisión del tema: primero, excluir de culpabilidad moral a los indios de América en las prácticas sexuales del matrimonio salvo en los casos en que se impidiera la generación de los hijos. Además, parece que Alonso está ya inserto en una mentalidad nominal en la que, a pesar de seguir las regulaciones de Trento tiene plena conciencia de que hay elementos prudenciales a tener en cuenta y que considera que los canonistas habían fijado monolíticamente algunos criterios; pretende fijar criterios generales cara a la finalidad sexual apartándose de interpretaciones necesarias ajenas al contexto y cultura con normatividades que descendían en casuística. Alonso recupera, en contraparte, un sentido más amplio del problema. En sus argumentaciones, aunque no hace explícito el método del sic et non medieval, lo sigue formulando, por lo que en ocasiones el lector cree haber entendido una conclusión, pero ésta al final parece cambiarse porque sienta otra al final de la argumentación. Por otra parte, Alonso puede denominarse un hombre de transición, alguien que reinterpreta las sentencias de la tradición y que intenta recuperar su auténtico sentido. Renueva desde un mismo espíritu, sigue las bases, aunque abre dudas y cuestionamientos. Aún no tiene una comprensión plena de la psicología humana en el ámbito familiar, aunque enfatiza constantemente en la igualdad entre hombres y mujeres. Abre la relación sexual matrimonial al tema del placer y de la afirmación positiva de la intimidad de los cónyuges, pero está ausente de sus argumentaciones el tema del diálogo, de 
la importancia de la obra conjunta cara a la pareja. Siempre el criterio lo pone desde la generación y se echa de menos un mayor énfasis en la comunicación entre los cónyuges y su prole. Alonso sigue inserto en una interpretación jurídica del matrimonio, la urgencia ante los nuevos tiempos en América lo exigía.

\section{Bibliografía}

Aquino, T. (2002). Suma de teología. España: Biblioteca de Autores Cristianos.

Aspe, V. (2016a). Integración cultural y ley natural en el Speculum Coniugiorum de Alonso de la Veracruz. En Revista Estudios, (32).

Aspe Armella, V. (2016b). La idea fundacional de justicia y derecho en el primer filósofo de América: una aproximación desde el De dominio infidelium et iusto bello de Alonso de la Veracruz. En Novenas Jornadas Internacionales de iustitia et iure: Figuras de la causalidad en la edad media y en el renacimiento. Pontificia Universidad Católica de Argentina.

Barp, L. (2009). Fray Alonso de la Vera Cruz. Speculum Coniugiorum. Espejo de Matrimonios. México: Universidad La Salle/UNAM. DAGAPA.

Basevi, C. (1992). Sexualidad humana y sacramentalidad, España: Rialp.

Carretas del Rincón, J. (1998). Sexo, fiesta y derecho. España: Rialp.

Ponce, C. (2007). Espejo de los cónyuges de Fray Alonso de la Vera Cruz. Antología. La problemática sobre el matrimonio y la ley natural en la formación de la nación mexicana. México: Los libros de Homero. 


\section{Resumen}

El propósito de este artículo es entender cómo concebía Alonso de la Veracruz la relación entre matrimonio, placer y sexualidad, mostrar que él hace esa interpretación basándose en el derecho civil y canónico de su tiempo, en el concepto tomista de ley natural y en algunos tratados europeos que se hicieron cargo de prácticas sexuales y de matrimonios ajenas al cristianismo aprovechando lo que el Concilio de Trento reguló.

Palabras clave: Alonso de la Veracruz, Tomás de Aquino, Speculum Coniugiorum.

\section{Abstract}

The purpose of this paper is to understand how Alonso de la Veracruz conceive the relation between marriage, pleasure and sexuality, and to show that his interpretation is based on civil and canonic right from his time, on the Aquinas' concept of natural law, and on some European treaties about sexual practices and marriages outside Christianity, according to regulations derived from the Council of Trent.

Key words: Alonso de la Veracruz, Thomas Aquinas, Speculum Coniugiorum. 